\title{
Compatibilization mechanism induced by organoclay in PMMA/PS blends
}

\author{
Julie Genoyer \\ Department of Polymer and Composites Technology and Mechanical Engineering, Mines Douai, Douai, France \\ and Department of Mechanical Engineering, École de Technologie Supérieure, Montreal, Québec H3C 1K3, Canada \\ Marcio Yee ${ }^{\text {a) }}$ \\ Metallurgical and Materials Engineering Department, University of São Paulo, São Paulo, Brazil \\ Jérémie Soulestin \\ Mines Douai, Department of Polymers and Composites Technology and Mechanical Engineering, Douai, France
}

Nicole Demarquette ${ }^{\text {b) }}$

Metallurgical and Materials Engineering Department, University of São Paulo, São Paulo, Brazil and Department of Mechanical Engineering, École de Technologie Supérieure, Montreal, Canada

(Received 29 November 2016; final revision received 13 April 2017; published 4 May 2017)

\begin{abstract}
In this work, the effect of adding organoclay (Cloisite 20A) to a poly(methyl metacrylate) (PMMA)/polystyrene (PS) blend was evaluated in order to understand the compatibilization mechanism taking place. The blend morphology was quantified using micrographs obtained by scanning electron microscopy and observed by transmission electron microscopy. The state of dispersion of the clay was studied using small angle X-ray scattering and wide angle X-ray scattering and by applying the Carreau-Yasuda with a yield stress model to small amplitude oscillatory shear (SAOS) data. Morphological analyses revealed that the clay was intercalated, that its addition resulted in a decrease in the size of the dispersed phase and that it was preferentially located at the interface, except in the case of saturated interfaces, in which case the remaining clay was dispersed in PMMA. By applying the simplified Palierne model to SAOS experiments, the interfacial tension between the polymers forming the blend was inferred and shown to decrease upon addition of clay. The relaxation spectra inferred from the SAOS data, using the Honerkamp and Weese method, revealed four relaxation times: Relaxation of PMMA and PS chains, relaxation of the droplet shape, as well as an additional relaxation phenomenon attributed to the Marangoni stress. Although Marangoni stresses have already been studied in the case of blends compatibilized by block copolymers, this is the first time that it has been evidenced in the case of a clay as compatibilizer. (C) 2017 The Society of Rheology. [http://dx.doi.org/10.1122/1.4982701]
\end{abstract}

\section{INTRODUCTION}

Polymer blends have been extensively used in the industry due to the interesting properties they present. Most polymers are thermodynamically immiscible, resulting in a multiphase material whose engineering properties can be controlled by their morphology. The blends' morphology is controlled during processing, but at the same time, the processability of polymer blends is influenced by the microstructure. The interplay between flow, morphology, and rheology is therefore a key point in tailoring the final material properties.

The immiscibility between the polymers forming the blends can however lead to a coarse morphology or even to phase separation, which is not interesting, as it leads to poor

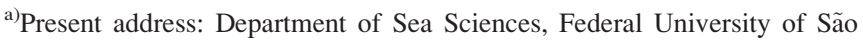
Paulo, Santos, Brazil.

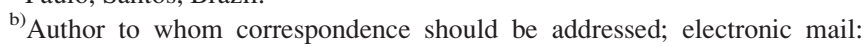
nicoler.demarquette@etsmtl.ca
}

physical properties. The addition of a so-called compatibilizer is a way to control the morphology over time [1,2]. Premade block copolymers are commonly used for this purpose and have been shown to be very efficient. However, their use involves significant drawbacks, including the fact that each chosen blend type needs to have a block copolymer with a tailored chemistry adapted to it, which in turn results in an expensive block copolymer design. At the industrial level, it is more common to create a compatibilizer during processing thanks to an interfacial reaction, followed by the use of so-called reactive compatibilization [3]. Although this has been shown to be efficient in stabilizing the blend morphology, when it is employed, it becomes difficult to quantify and adjust the amount of compatibilizer created, as well as its exact structure. In the case of a droplet dispersion, as the compatibilizers settle at the interface, the addition leads to a reduction in the dispersed phase size [4]; a stabilization of morphology, inhibiting the dispersed phase coalescence [5]; a decrease in interfacial tension [4,6], and the presence 
of an additional relaxation phenomenon [7-9]. All this leads to an improvement in the blend properties.

Recently, some studies have shown that the addition of nanoparticles could have a similar effect as adding compatibilizer, as in some cases, the former can result in a reduction in the dispersed phase size [10], morphology stabilization [11], as well as a decrease in interfacial tension $[10,12]$, when the nanoparticles are located at the interface. However, if the nanoparticles are located in a single phase other possible mechanisms can be considered: Change in the viscosity of the phases, immobilization of the dispersed drops by the creation of a physical network of particles in the matrix (possible when concentration of solid above the percolation threshold) or the strong interaction of polymer chains onto the solid particles inducing steric hindrance $[13,14]$. Therefore, the localization of the nanoparticles is a key to understanding the compatibilization mechanism. This localization is a function of the nature of the nanoparticles, and thus depends on the size, shape, and chemical surface of the nanoparticles. That is why most often, nanoparticles are organomodified either by chemical grafting [15-17] or by ionic exchange [18-21] in order to be more compatible with blend components. However, while some studies have shown that adding organoparticles could be similar to adding block copolymers, when the latter are located at the interface, no additional relaxation phenomenon has as yet been observed.

The linear viscoelastic rheological behavior of a blend can provide information on the morphology and the interfacial tension of the blended component: Small amplitude oscillatory shear (SAOS) experiments show an increase in elasticity at low frequencies, resulting in a shoulder on the storage modulus curve. This increase is associated with the relaxation of the shape of the droplets $\left(\tau_{F}\right)$, which were previously deformed by the stress applied [22]. In the case of compatibilized blends, an additional relaxation time $\left(\tau_{\beta}\right)$ may be observed, as already mentioned. Van Hemelrjick et al. showed that $\tau_{F}$ depends mainly on the concentration of the dispersed phase, whereas $\tau_{\beta}$ strongly depends on the concentration of compatibilizer [23]. Therefore, the latter relaxation time is believed to be due to the presence of copolymer at the interface, and especially to the Marangoni stress illustrated in Fig. 1 [7,24,25]. This Marangoni stress occurs when the compatibilizer is not distributed equally around the droplet. When two droplets approach, the matrix in between them will flow elsewhere and drag the compatibilizer with it. It results in a gradient in compatibilizer concentration on the surface of the droplets. Because of that, an

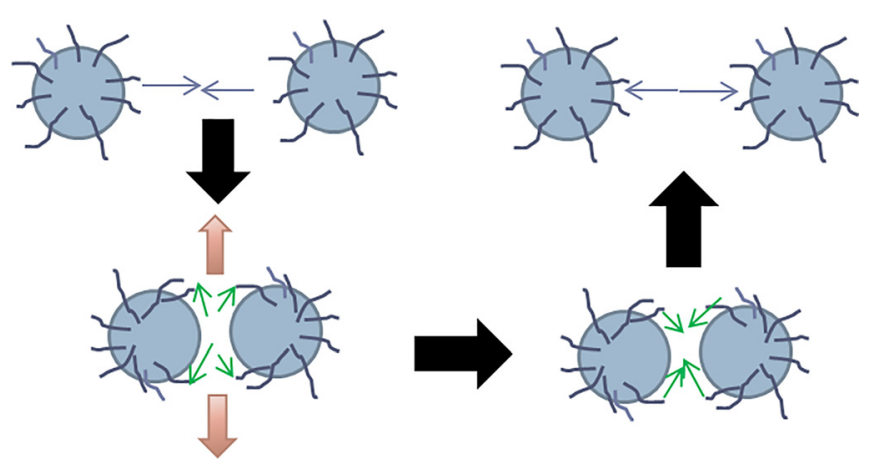

FIG. 1. Illustration of the Marangoni stress. opposite force will cause the compatibilizer to come back equally distributed on the surface, thereby preventing coalescence. This is called the Marangoni stress. In this regard, Jeon and Macosko [26] showed gradients in block copolymer concentration during flow by visualizing a fluorescent polystyrene/ poly(methylmethacrylate) (PS-PMMA) copolymer at the surface of a PMMA droplet in a PS matrix. On those matters, rheology can provide information on the morphology and compatibilization mechanism in a blend.

In order to better study the Marangoni stress relaxation, relaxation spectra can be recovered from classical SAOS measurements by the method of Honerkamp and Weese [27]. Usually, on a relaxation spectrum, the two relaxation times, each corresponding to a phase, can be seen, followed by a longer relaxation time induced by the relaxation of the shape of the droplets $\tau_{F}$. Upon the addition of block copolymer, a fourth relaxation time $\tau_{\beta}$ can be observed between 10 and $100 \mathrm{~s}$ in some cases. However, this last relaxation phenomenon can be observed at even longer times that are hard to reach with only SAOS measurements. One possibility for avoiding this problem is to use creep experiments for complementary data over longer times [28].

Several models have been developed to link the rheological behavior of polymer blends to their morphology, composition, and interfacial tension between components. One such model is the Palierne model, which predicts the rheological behavior of a blend formed by two viscoelastic polymers [29]. The polymers should be viscous enough to render bulk forces such as gravitation and inertia negligible, and the emulsion should be monodispersed and diluted. This model is made to predict the behavior of blends in the linear viscoelastic regime so at small and slow deformations. As such, the constitutive equations which relate stress to deformations are linear.

Palierne developed a constitutive equation to describe the complex modulus $G(\omega)_{b}^{*}$ of the blend as a function of the modulus of the matrix $G(\omega)_{M}^{*}$ and the dispersed phase $G(\omega)_{I}^{*}$ as written below

$$
\begin{aligned}
G_{b}^{*}=G_{M}^{*}\left[\frac{1+\frac{3}{2} \sum_{I} \frac{\Phi_{I} E_{I}}{D_{I}}}{1-\sum_{I} \frac{\Phi_{I} E_{I}}{D_{I}}}\right], \\
E_{I}=2\left(G_{I}^{*}-G_{M}^{*}\right)\left(19 G_{I}^{*}+16 G_{M}^{*}\right)+\frac{48 \beta^{\prime} \alpha^{0}}{R} \\
+\frac{32 \beta^{\prime \prime}\left(\alpha^{0}+\beta^{\prime}\right)}{R^{2}}+\frac{8 \alpha^{0}}{R}\left(5 G_{I}^{*}+2 G_{M}^{*}\right) \\
+\frac{2 \beta^{\prime}}{R}\left(23 G_{I}^{*}-16 G_{M}^{*}\right)+\frac{4 \beta^{\prime \prime}}{R}\left(13 G_{I}^{*}+8 G_{M}^{*}\right), \\
D_{I}=2\left(G_{I}^{*}-G_{M}^{*}\right)\left(19 G_{I}^{*}+16 G_{M}^{*}\right)+\frac{48 \beta^{\prime} \alpha^{0}}{R} \\
+ \\
+\frac{32 \beta^{\prime \prime}\left(\alpha^{0}+\beta^{\prime}\right)}{R^{2}}+\frac{40 \alpha^{0}}{R}\left(G_{I}^{*}+G_{M}^{*}\right) \\
+\frac{2 \beta^{\prime}}{R}\left(23 G_{I}^{*}+32 G_{M}^{*}\right)+\frac{4 \beta^{\prime \prime}}{R}\left(13 G_{I}^{*}+12 G_{M}^{*}\right),
\end{aligned}
$$


where $\alpha^{0}$ is the interfacial tension, $R$ is the radius of the droplets, $\Phi$ is the dispersed phase volume concentration, $\beta^{\prime}$ is the interfacial dilatation modulus relative to the area variation, and $\beta^{\prime \prime}$ is the interfacial shear modulus relative to shear without change of area [29].

To simplify the model in the case of polydispersed blends, Graebling et al. showed that an average radius $R_{v}$ can be used up to a polydispersity of 2.3 [22].

A second simplification often used is to take $\beta^{\prime}=\beta^{\prime \prime}=0$, which corresponds to a constant interfacial tension despite the addition of interfacial agents. This version of Palierne is the most simple, and the most used [22,30]. The expression has often been used to fit the storage modulus in order to find the interfacial tension or the average radius of droplets, because these two parameters are the only unknowns. These expressions allow the following relaxation time to be found:

$$
\tau_{\mathrm{F}}=\frac{\left(\frac{R_{v} \eta_{M}}{4 \alpha}\right)(19 p+16)(2 p+3-2 \Phi(p-1))}{10(p+1)-2 \Phi(5 p+2)}
$$

where $R_{v}$ is the average droplet radius, $\alpha$ is the constant interfacial tension, and $p$ is the viscosity ratio.

This time corresponds to the relaxation of the droplets' shape. The original Palierne model was also modified by Jacobs et al., who noticed that the two interfacial parameters $\beta^{\prime}$ and $\beta^{\prime \prime}$ of the original version had symmetrical roles in the equations [31]. In that regard, they decided to consider one of them constant, and set the other to zero. This approach requires the existence of an additional shape relaxation time other than the drops' relaxation time. In this work, the following expression was used for the relaxation times:

$$
\begin{gathered}
\tau_{F}=\frac{\lambda_{12}}{2}\left(1-\left(1-\frac{4 \lambda_{11}}{\lambda_{12}}\right)^{0.5}\right), \\
\tau_{\beta}=\frac{\lambda_{12}}{2}\left(1+\left(1-\frac{4 \lambda_{11}}{\lambda_{12}}\right)^{0.5}\right),
\end{gathered}
$$

with

$$
\begin{aligned}
& \lambda_{11}=\frac{R_{v} \eta_{m}}{4 \alpha} \frac{(19 p+16)(2 p+3-2 \Phi(p-1))}{10(p+1)+\frac{\beta_{20}}{\alpha}(13 p+12)-2 \Phi\left((5 p+2)+\frac{\beta_{20}}{2 \alpha}(13 p+8)\right)} \\
& \lambda_{12}=\frac{R_{v} \eta_{m}}{8 \beta_{20}} \frac{10(p+1)+\frac{\beta_{20}}{\alpha}(13 p+12)-2 \Phi\left((5 p+2)+\frac{\beta_{20}}{2 \alpha}(13 p+8)\right)}{(1-\Phi)} .
\end{aligned}
$$

In the next work, the rheological behavior of PMMA/PS blends compatibilized by a clay (Cloisite 20A) was studied. PMMA/PS blends are often used in research on compatibilization of polymer blends as it is a "model" blend with a relatively simple rheological behavior. The morphology, the dispersion state, and the localization of clay in the blends were assessed. The interfacial tension was found using the simplified Palierne model. Relaxation phenomena were also studied by using the relaxation spectra inferred from SAOS measurements.

\section{MATERIALS AND METHODS}

\section{A. Materials}

PMMA (DHAF grade) from Metacrill S.A. and PS (N1841 grade) from InNova S.A. were used in this study. The characteristics of the polymers are reported in Table I. Cloisite 20A was purchased from Southern Clay.

\section{B. Blending}

Blends of PMMA/PS were prepared in 90/10 and 70/30 weight concentrations. For each concentration in PMMA and
PS, several blends were prepared with different concentrations of Cloisite 20A ranging from 0 to $8 \mathrm{wt}$. \% with respect to the dispersed phase PS. All the percentages in this paper are weight percentage and clay weight percentage is always given with respect to PS.

The blends were prepared using a Haake PolyLab 900/ Rheomix 600p batch mixer at $200^{\circ} \mathrm{C}$ and $50 \mathrm{rpm}$ after PMMA was dried at $60^{\circ} \mathrm{C}$ for $12 \mathrm{~h}$. They were prepared in two steps: In the first step, the nanoclay was mixed with the minor phase (PS) for $5 \mathrm{~min}$, and in the second, PS+nanoclay was mixed with the matrix (PMMA) for $7 \mathrm{~min}$. The clay was added to the PS because of the affinity between the polymer and the clay

\begin{tabular}{|c|c|c|c|c|c|}
\hline Polymer & $\begin{array}{c}M_{w} \\
(\mathrm{~g} / \mathrm{mol})\end{array}$ & $\begin{array}{c}M_{n} \\
(\mathrm{~g} / \mathrm{mol})\end{array}$ & $M_{w} / M_{n}$ & $\begin{array}{r}\text { Viscosity } \\
\left(\eta_{0}\right)(\mathrm{Pa} \mathrm{s}) \\
\text { at } 200^{\circ} \mathrm{C}\end{array}$ & $\begin{array}{r}\text { Viscosity } \\
\left(\eta_{0}\right)(\mathrm{Pa} \mathrm{s}) \\
\text { at } 220^{\circ} \mathrm{C}\end{array}$ \\
\hline PMMA & 65000 & 31000 & 2.1 & 24000 & 4300 \\
\hline PS & 198000 & 87000 & 2.2 & 3200 & 2100 \\
\hline
\end{tabular}
(see section "Dispersion state of clay"). In the case of the nonmodified blends, the minor phase was processed twice in order to ensure it had the same thermal history.

TABLE I. Properties of the polymers. 


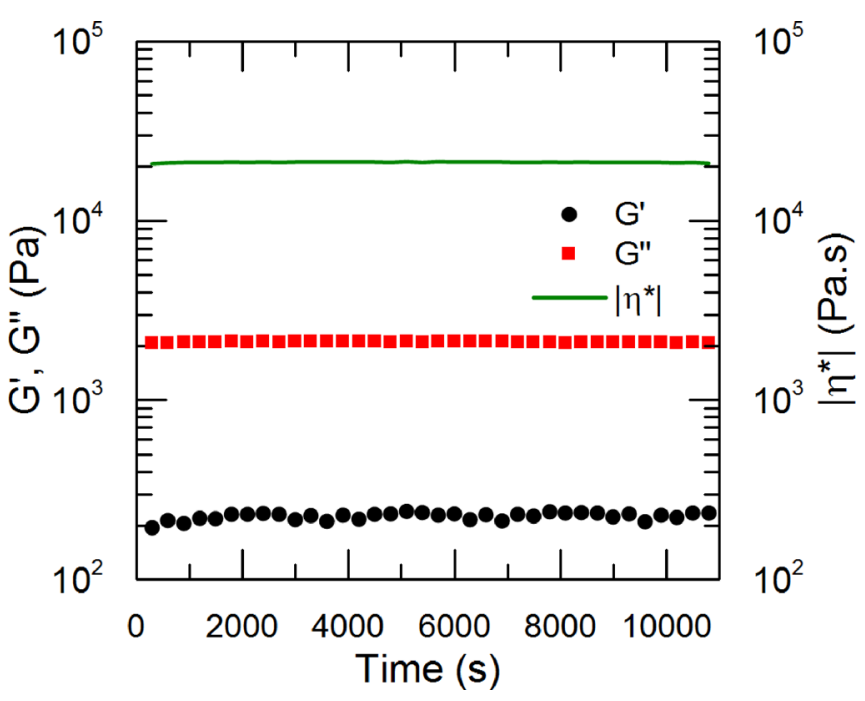

FIG. 2. Variation of the complex viscosity, the storage modulus, and the loss modulus over time of the 90/10 (PMMA/PS) blend at $200^{\circ} \mathrm{C}$ and $0.1 \mathrm{rad} / \mathrm{s}$.
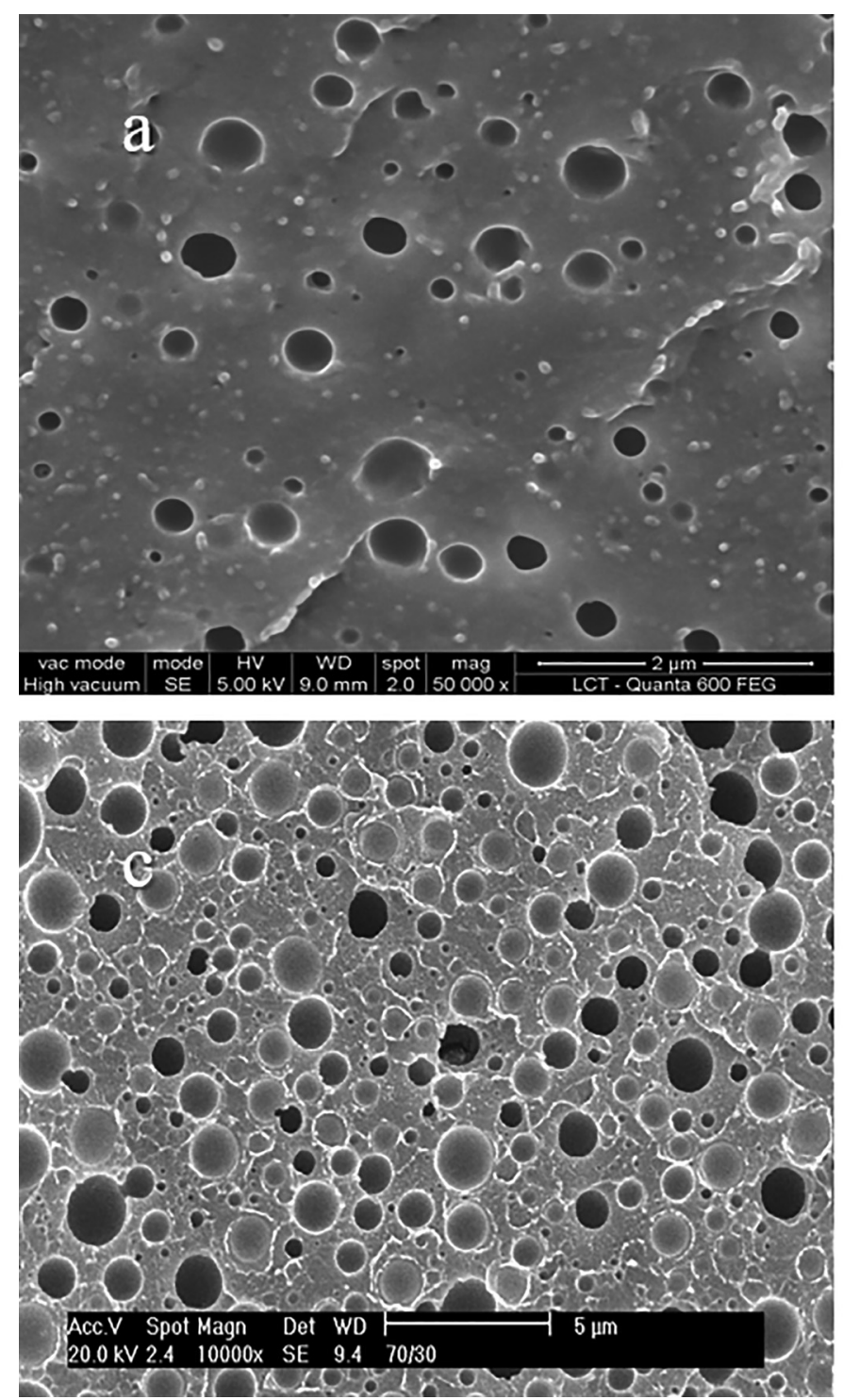

\section{Characterizations}

Samples for rheological and morphological analyses were obtained by compression molding. Disks with a $25 \mathrm{~mm}$ diameter and $1 \mathrm{~mm}$ thickness were molded at $200^{\circ} \mathrm{C}$ under $18 \mathrm{MPa}$ for $10 \mathrm{~min}$.

The rheological characterization of pure phases, PMMA/ PS blends to which clay was or was not added, was performed using a stress-controlled MCR 501 rheometer from Anton Paar. Measurements were carried out under dry nitrogen atmosphere. A parallel-plate geometry was used with a gap size of $0.9 \mathrm{~mm}$ and a plate diameter of $25 \mathrm{~mm}$. Time sweep tests were performed in order to check the thermal stability of the samples (see an example in Fig. 2).

Strain sweep tests were carried out for all blends and pure polymers to define the linear viscoelasticity region. Finally, dynamic frequency sweep tests were performed for all blends and pure polymers at 200 and $220^{\circ} \mathrm{C}$. The strain varied from $1.5 \%$ to $6 \%$. The measurements were performed from 300 to $0.01 \mathrm{~Hz}$. The zero-shear viscosity of the
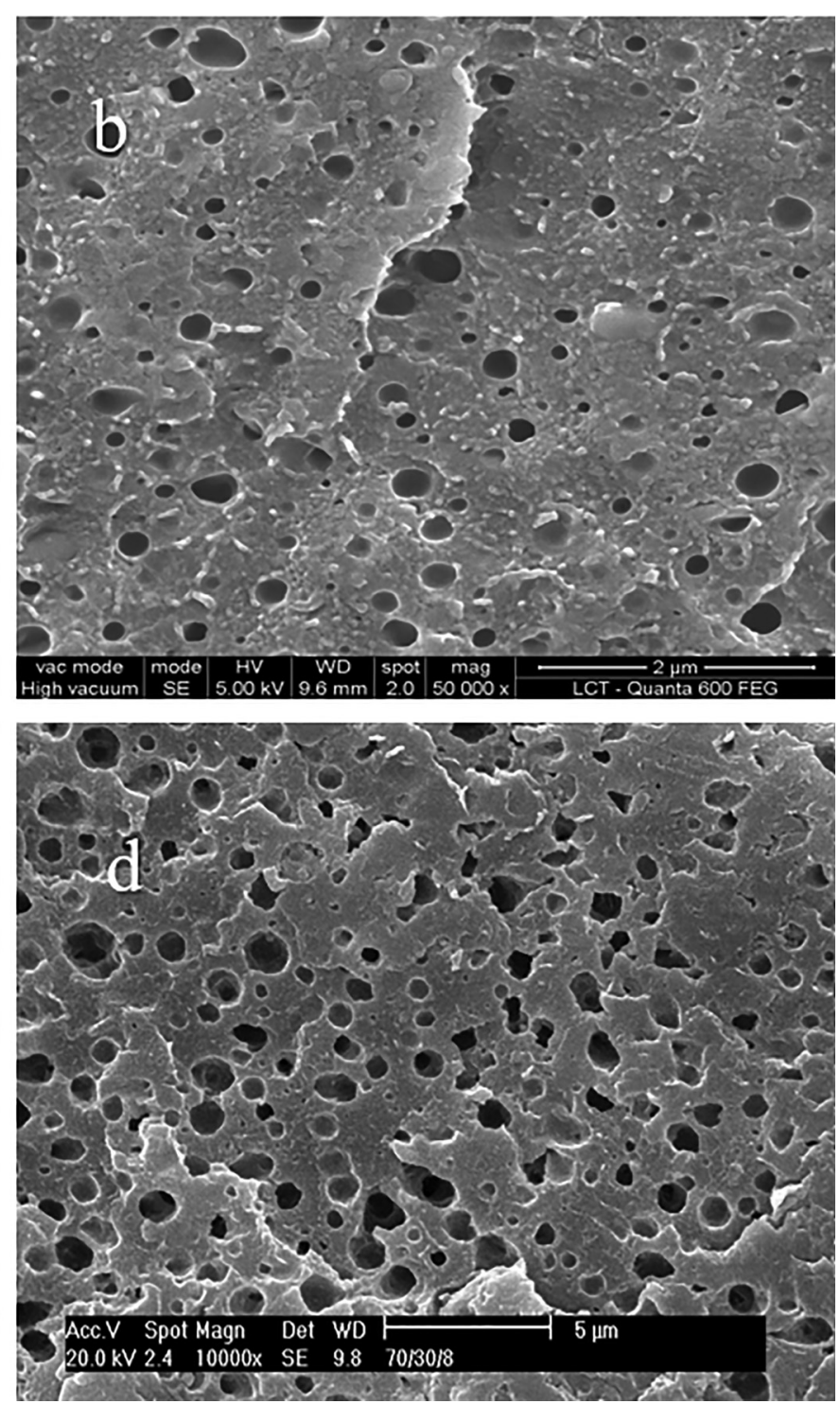

FIG. 3. Morphology of blends for a 90/10 composition (a) with and (b) without the addition of $8 \%$ Cloisite 20A, and for a $70 / 30$ composition (c) without and (d) with addition of $8 \%$ of Cloisite $20 \mathrm{~A}$. 
individual phases necessary to calculate the interfacial tension between the components of the blend, using Palierne's model, was determined using the curve of complex viscosity ( $\mathrm{Pa} \mathrm{s}$ ) versus frequency ( $\mathrm{rad} / \mathrm{s}$ ) obtained from dynamic frequency sweep tests. Rheological experiments were shown to be reproducible within $5 \%$.

The morphology was characterized by scanning electron microscopy (SEM) using a Philips model XL 30 microscope as described by Yee et al. [8,24]. The samples were previously fractured in liquid nitrogen and covered with gold using a Balzers sputter coater, model SCD-050. The PS was extracted using cyclohexane at room temperature under continuous stirring for $6 \mathrm{~h}$ in order to improve the contrast of pictures. The morphology was quantified using an image analysis software package (KS 300) after analysis of the SEM photomicrographs. About 1000 particles were considered for each sample. For the calculation of the average droplet radius, Saltikov's correction was used [32]. This correction takes into account the polydispersity of the morphology of the samples and the fact that the fracture in the samples does not always occur at the maximum diameter of the droplets of the dispersed phase.

Small angle X-ray scattering (SAXS) experiments were carried out using the synchrotron source from the National Synchrotron Light Laboratory (LNLS), Campinas, Brazil, to evaluate the state of dispersion of the clays within the polymers. The wavelength of the X-Ray beam was $1.488 \AA$. The sample-to-detector distance was 950 or $1125 \mathrm{~mm}$. Other samples were subsequently characterized using wide angle X-ray scattering (WAXS) on a PANalytical diffractometer, model X'Pert Pro, with a $\mathrm{CuK} \alpha$ radiation of wavelength $0.154 \mathrm{~nm}$ scattering at ambient temperature.

In order to obtain transmission electron microscopy (TEM) pictures, samples were sectioned at room temperature, with a thickness of $\sim 90 \mathrm{~nm}$ with a Leica Microsystems UCT ultramicrotome, and transferred to 200-mesh Cu TEM grids with carbon supported film. The images were collected on the FEI Tecnai G2 F20 S/TEM equipped with a Gatan Ultrascan 4000 CCD Camera Model 895 at an accelerating voltage of $200 \mathrm{kV}$.

\section{RESULTS AND DISCUSSION}

\section{A. Morphology}

SEM observations were used to assess the morphology of the blends. Figure 3 shows the morphology of 90/10 and 70/ 30 blends with and without the addition of $8 \%$ of clay. A droplet dispersion morphology type is observed for all the blends. According to Figs. 3(a) and 3(c), the size of the droplets increases as a function of the concentration of PS. The experimental values of the volume average droplet radius $\left(R_{v}\right)$ and the polydispersity $\left(R_{v} / R_{n}\right)$ are reported in Table II, where the increase in the radius of the droplets is quantitatively confirmed. This expected behavior is generally due to an increase in the coalescence of the dispersed phase when its concentration increases [5,32].

Moreover, a decrease of $R_{v}$ of $34 \%$ upon addition of clay can be seen, which illustrates a compatibilizing effect of the clay. However, this reduction in droplet diameter size is smaller than what we obtained previously when using a random copolymer [24]. This may be due to a different interface coverage due to the less adequate chemistry when compared to that of the copolymer.

As stated in the introduction, the compatibilization mechanism can have several explanations. To understand it, the dispersion and localization of clay in the blends must be known.

\section{B. Dispersion state of clay}

The basal spacing of Cloisite $20 \mathrm{~A}$ alone and in the polymers was estimated from WAXS and SAXS patterns. The values of $d_{(001)}$ are reported in Tables III and IV.

TABLE II. Volume average radius $\left(R_{v}\right)$ and polydispersities $\left(R_{v} / R_{n}\right)$ of the dispersed phase.

\begin{tabular}{|c|c|c|c|c|c|c|}
\hline \multirow[b]{2}{*}{ Composition } & \multirow[b]{2}{*}{$\begin{array}{l}\text { \% Compatibilizer with } \\
\text { respect to PS }\end{array}$} & \multirow[b]{2}{*}{$\begin{array}{l}\% \text { Compatibilizer with respect } \\
\text { to the whole blend }\end{array}$} & \multicolumn{2}{|c|}{ Cloisite 20A } & \multicolumn{2}{|c|}{ PMMA-ran-PS ${ }^{a}$} \\
\hline & & & $R_{v}(\mu \mathrm{m})$ & $\frac{R_{v}}{R_{n}}$ & $R_{v}(\mu \mathrm{m})$ & $\frac{R_{v}}{R_{n}}$ \\
\hline \multirow[t]{4}{*}{$90 / 10$} & 0 & 0 & $\begin{aligned} & 0.125 \\
\pm & 0.015\end{aligned}$ & 1.8 & $\begin{array}{c}0.125 \\
\pm 0.015\end{array}$ & 1.8 \\
\hline & 1 & 0.1 & - & - & - & - \\
\hline & 4 & 0.4 & $\begin{array}{c}0.094 \\
\pm 0.005\end{array}$ & 2 & $\begin{array}{c}0.060 \\
\pm 0.007\end{array}$ & 1.9 \\
\hline & 8 & 0.8 & $\begin{array}{c}0.083 \\
\pm 0.009\end{array}$ & 1.8 & $\begin{array}{c}0.050 \\
\pm 0.007\end{array}$ & 1.8 \\
\hline \multirow[t]{4}{*}{$70 / 30$} & 0 & 0 & $\begin{array}{c}0.620 \\
\pm 0.080\end{array}$ & 2.3 & - & - \\
\hline & 1 & 0.3 & $\begin{array}{c}0.580 \\
\pm 0.070\end{array}$ & 2.4 & - & - \\
\hline & 4 & 1.2 & $\begin{array}{c}0.482 \\
\pm 0.070\end{array}$ & 2.4 & - & - \\
\hline & 8 & 2.4 & $\begin{array}{c}0.437 \\
\pm 0.080\end{array}$ & 2.6 & - & - \\
\hline
\end{tabular}

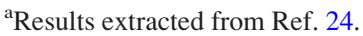


TABLE III. SAXS results for PMMA+(PS + C) blends.

\begin{tabular}{lcccc}
\hline \hline Composition & \% Cloisite 20A & $q(\AA-1)$ & $d_{(001)}(\mathrm{nm})$ & $\Delta d_{(001)}(\mathrm{nm})$ \\
\hline Cloisite 20A & - & 2.57 & 2.44 & - \\
PS & 1 & 1.68 & 3.73 & 1.29 \\
\multirow{2}{*}{$70 / 30$} & 8 & 1.76 & 3.56 & 1.12 \\
& 1 & 1.71 & 3.67 & 1.22 \\
& 4 & 1.74 & 3.61 & 1.16 \\
$90 / 10$ & 8 & 1.73 & 3.63 & 1.18 \\
& 1 & 1.74 & 3.61 & 1.16 \\
& 4 & 1.71 & 3.67 & 1.22 \\
& 8 & 1.74 & 3.61 & 1.16 \\
\hline \hline
\end{tabular}

It can be seen that the basal spacing increases when clay is dispersed in blends or pure polymers, indicating that chains of polymer are intercalated between the clay platelets. Parts of the clay platelets might however be exfoliated within the polymer. It can be seen from Table III that the interlayer spacing between the clay platelets is larger for the composites with $1 \mathrm{wt}$. \% clay than for that with $8 \%$. This could be due to the fact that at higher clay content, the formation of aggregates could occur more easily because of the interactions between particles. A similar behavior was observed by Amurin et al. [34].

Figure 4 shows the complex viscosities measured for pure PMMA and PS which clay was added. An increase in the complex viscosity at low frequencies can be observed with the addition of clay in the case of PMMA. This addition does not have a large influence on the rheological behavior of PS, except when $8 \%$ is added. In this case, the viscosity of the material increases for the whole frequency range, indicating that it acts as a filler.

The complex viscosities were fitted to the CarreauYasuda model to which a yield stress had been added, as described by Vergnes [35], in order to obtain further information on the dispersion state of clay. According to Vergnes, the complex viscosity of a material to which clay has been added can be written as follows:

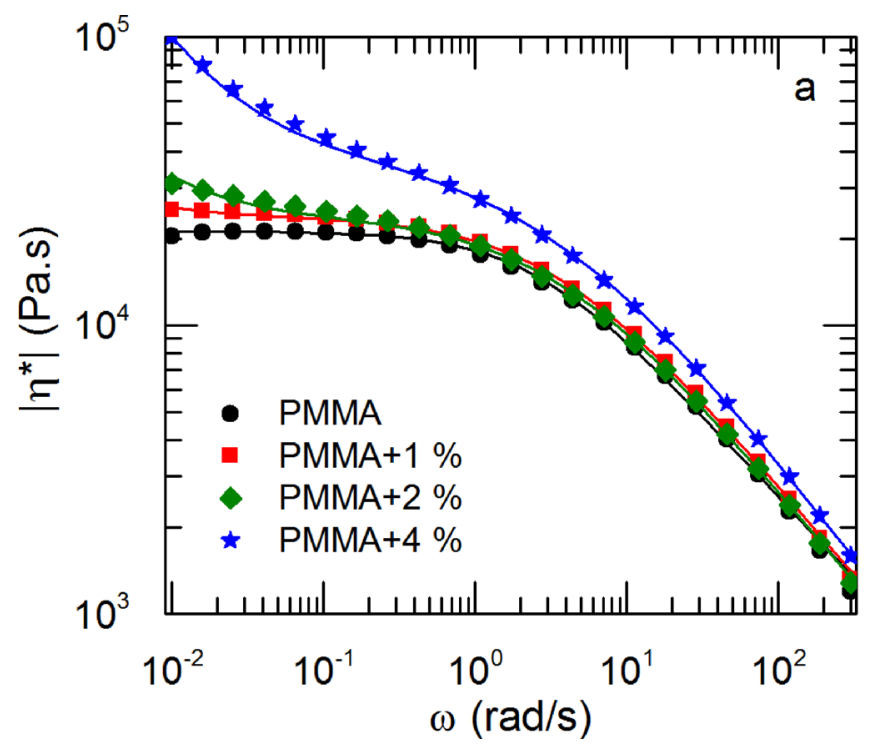

TABLE IV. WAXS results.

\begin{tabular}{lcccc}
\hline \hline Composition & \% Cloisite 20A & $2 \theta_{2}(\mathrm{deg})$ & $d_{(100)}(\mathrm{nm})$ & $\Delta d_{(001)}(\mathrm{nm})$ \\
\hline PS & 8 & 5.04 & 3.51 & 1.07 \\
PMMA & 1 & 5.07 & 3.49 & 1.05 \\
& 4 & 4.99 & 3.54 & 1.10 \\
\hline & & &
\end{tabular}

where $\sigma_{0}$ is the melt yield stress, $\eta_{0}$ is the zero shear viscosity, $\lambda$ is the time constant, $n$ is the power law index, and $a$ is the Yasuda parameter.

This model contains five parameters that were adjusted to obtain the best fit with the experimental data. Figure 4 shows that the fits (lines) correspond well to the experimental data (points) in the complex viscosity curves. The corresponding values for the parameters are reported in Table V.

The only parameters that vary significantly are the zero shear viscosity and the yield stress. This is in agreement with the work of Lertwimolnum and Vergnes, who noticed the same effect [36]. The increase in zero shear viscosity is particularly noticeable for high clay contents (PMMA $+4 \%$ and PS $+8 \%$ ) and seems to be linked to the combined effect of high clay levels and partly exfoliated clay. On the other hand, the yield stress is essentially affected by the exfoliation of clay [35]: For PS $+8 \%$, the viscosity has doubled, but the yield stress had almost no increase. In the case of PMMA + $4 \%$, the viscosity has doubled as well, but the yield stress dramatically increased compared to pure PMMA and PS + $8 \%$. This indicates that clay has more affinity with PMMA, and as a result, if the clay were to disperse in one of the phases, it would be PMMA. In the blending method, the nanoparticles were dispersed in PS prior to mixing the whole blend. The goal was to locate clay at the interface between PMMA and PS, thanks to the migration of clay nanoparticles

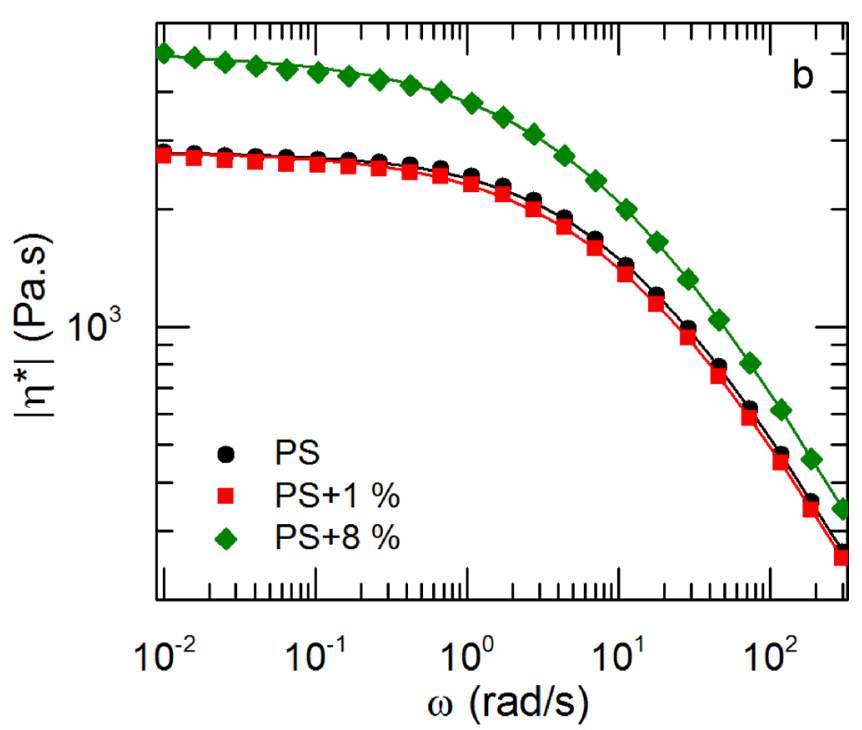

FIG. 4. Complex viscosity of (a) pure PMMA and (b) pure PS with different levels of Cloisite $20 \mathrm{~A}$ at $200^{\circ} \mathrm{C}$. Lines represent the fit of Carreau-Yasuda with yield stress equation. 
TABLE V. Values of parameters of Carreau-Yasuda with yield stress found by fitting with experimental values.

\begin{tabular}{|c|c|c|c|c|c|c|c|}
\hline \multirow{2}{*}{$\begin{array}{l}\text { Matrix } \\
\% \text { clay }\end{array}$} & \multicolumn{4}{|c|}{ PMMA } & \multicolumn{3}{|c|}{ PS } \\
\hline & 0 & 1 & 2 & 4 & 0 & 1 & 8 \\
\hline$\sigma_{0}(\mathrm{~Pa})$ & 0.00 & 21.0 & 93.4 & 610 & 0.00 & 0.00 & 0.96 \\
\hline$\eta_{0}(\mathrm{~Pa} \mathrm{~s})$ & 21000 & 23740 & 23740 & 40000 & 2800 & 2800 & 4920 \\
\hline$\lambda(\mathrm{s})$ & 0.24 & 0.29 & 0.29 & 0.31 & 0.09 & 0.09 & 0.12 \\
\hline$a$ & 0.91 & 0.92 & 0.85 & 0.68 & 0.72 & 0.66 & 0.63 \\
\hline$n$ & 0.34 & 0.37 & 0.36 & 0.30 & 0.31 & 0.30 & 0.29 \\
\hline
\end{tabular}

during blending. The localization of clay is confirmed below by TEM and rheological experiments.

\section{Localization of clay}

TEM pictures showed that in a 70/30/8 blend, clay is located both at the interface and in PMMA [see Fig. 5(a)]. For $90 / 10 / 8$ blends, clay is located mainly at the interface [see Fig. 5(b)]. These results indicate that while clay is located preferably at the interface, however, $8 \%$ of clay in $70 / 30$ blends leads to a saturated interface, and excess clay goes to PMMA.

Figure 6 shows the rheological behavior of pure blends. It can be seen that for low frequencies, the storage moduli of the 70/30 blends exhibit a shoulder corresponding to the presence of a dispersed phase. This shoulder cannot be well observed for lower dispersed phase concentrations, as expected in the work of Graebling et al. [22].

Figure 7 shows the rheological results for blends with different amounts of clay. The rheological behavior of 90/10 blends does not seem to be affected by the presence of clay, most likely due to a too low concentration of both dispersed phase and clay. Conversely, a shoulder, typical to immiscible blend rheological curves, is clearly visible in the case of 70/ 30 blends, which also shows different behaviors depending on the amount of clay.

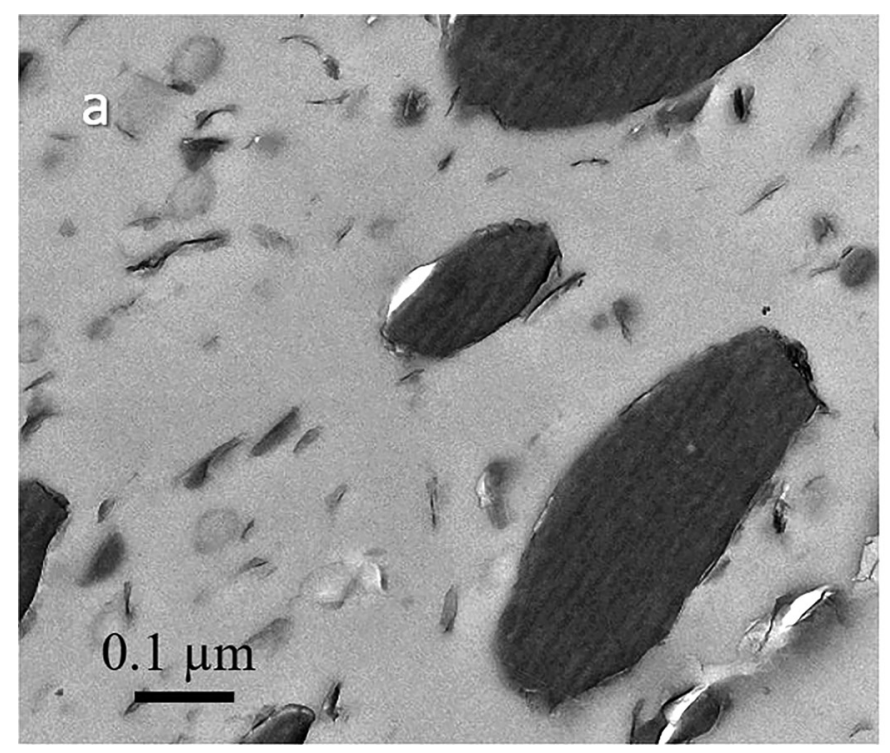

Figure 8 compares the rheological behavior of 70/30/ 8 blends with that of the pure polymers with clay. $8 \%$ of clay with respect to PS corresponds to $3.4 \%$ of clay with respect to PMMA, and as such, the 70/30/8 curve can be compared to PMMA $+4 \%$ if all the clay is dispersed in PMMA, and to PS $+8 \%$ if all the clay is dispersed in PS. In the $70 / 30 /$ 8 curve, the shoulder due to the presence of droplets disappears, and a plateau is observed at low frequencies, mimicking the behavior of PMMA $+4 \%$ of clay.

There are several phenomena that can influence the evolution of the storage modulus at low frequencies: The droplet relaxation, the interface relaxation, and the presence of clay in one of the phases. In order to try to differentiate those phenomena, the simplified Palierne model with the approximation of Graebling et al. [22] was fitted to a 70/30 pure blend, leading to an interfacial tension of $0.89 \mathrm{mN} / \mathrm{m}$. The fit is presented in Fig. 9(a). The blends with clay were then compared to their predictions using the same Palierne model with $R_{v}$ extracted from Table II and the interfacial tension defined previously $(0.89 \mathrm{mN} / \mathrm{m})$. This model only considers the droplet shape relaxation.

If we compare the theoretical predictions of Palierne's model to the experimental curves (see Fig. 9), it can be seen that for 70/30/1, the fit corroborates the experimental data, and that a discrepancy between theoretical predictions and experimental data starts to surface for clay concentrations of $4 \%$. Palierne's model predicts a shoulder shifting slightly to a higher frequency, and hence to shorter relaxation times induced by the decrease in the dispersed phase size, upon addition of clay, whereas the experimental data show a gradual increase at low frequencies and the disappearance of the shoulder in favor of this increase, starting at $4 \%$ of clay. The loss modulus is also increased as compared to predictions, indicating an effect on the viscosity of the blend.

To better visualize the difference with the theory, the experimental storage modulus $\left(G_{e}^{\prime}\right)$ was plotted as a function of the theoretical storage modulus $\left(G_{p}^{\prime}\right)$ (see Fig. 10). As

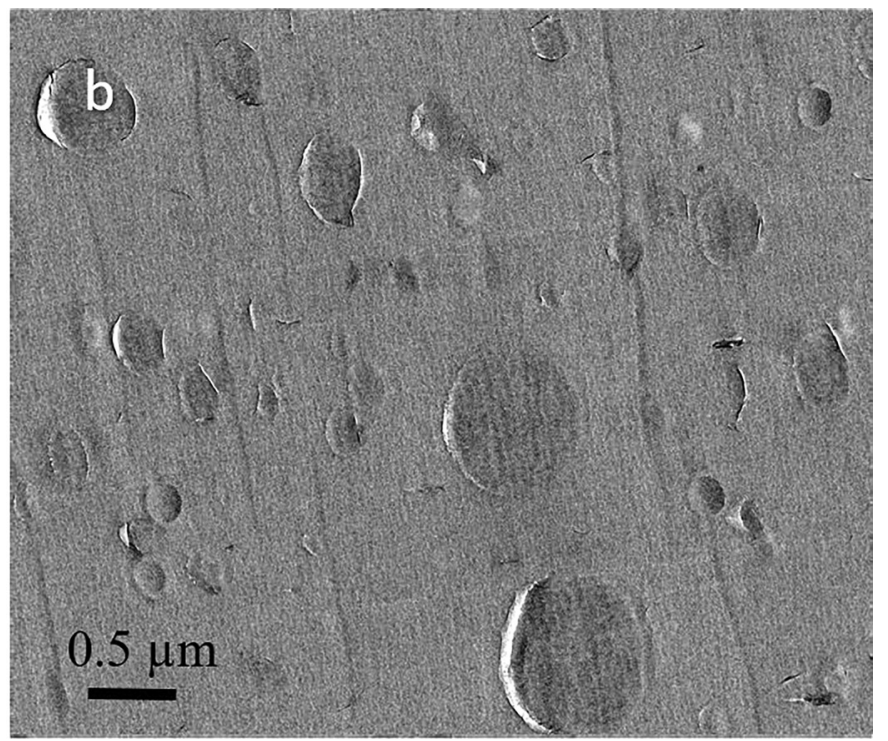

FIG. 5. Typical TEM picture of 70/30/8 (a) and 90/10/8 (b) blends. 


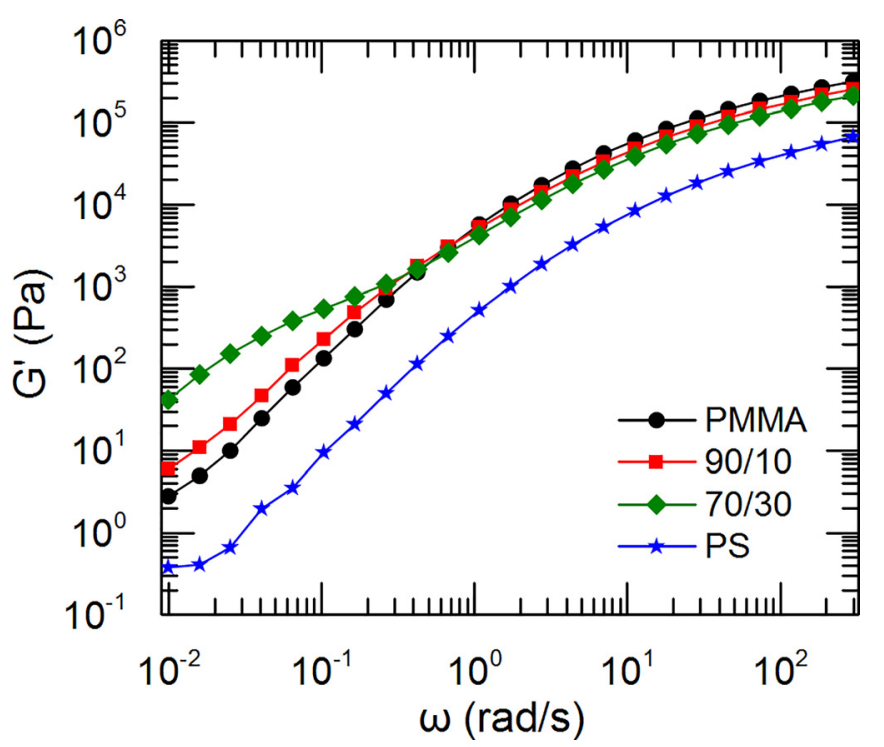

FIG. 6. Storage moduli of PMMA and PS and of pure blends $90 / 10$ and $70 /$ 30 , in order to emphasis the effect of dispersed phase at $200^{\circ} \mathrm{C}$.

expected, the pure blend and 70/30/1 had no noticeable deviation from the theory, whereas 70/30/4 and 70/30/8 showed a significant deviation at low frequencies. As the model takes into account the shape relaxation of the droplets, the deviation from the line could represent the effect of nanoparticles at the interface or in one of the phases. Figure 5 shows that for a 70/30/8 blend, the clay was present at the interface as well as in the PMMA phase. For a 90/10/8 blend, clay was located only at the interface. The rheological behavior changes from a typical blend behavior to a behavior close to a PMMA filled with clay for $4 \%$ and $8 \%$ of clay in $70 / 30$ blends. This have not been observed for $90 / 10$ blends, therefore, it is considered that the interface is saturated in $70 / 30 /$ 8 and 70/30/4 blends and the excess of clay disperse in the matrix.

The concentration of clay at which the interface is saturated can be evaluated by the following equation used by Ray et al. [21]:

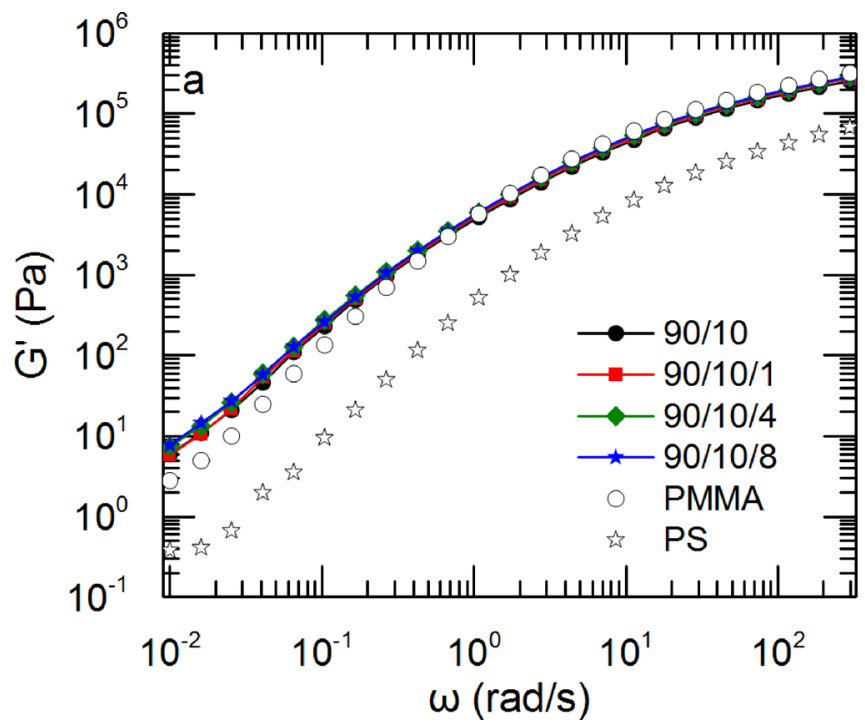

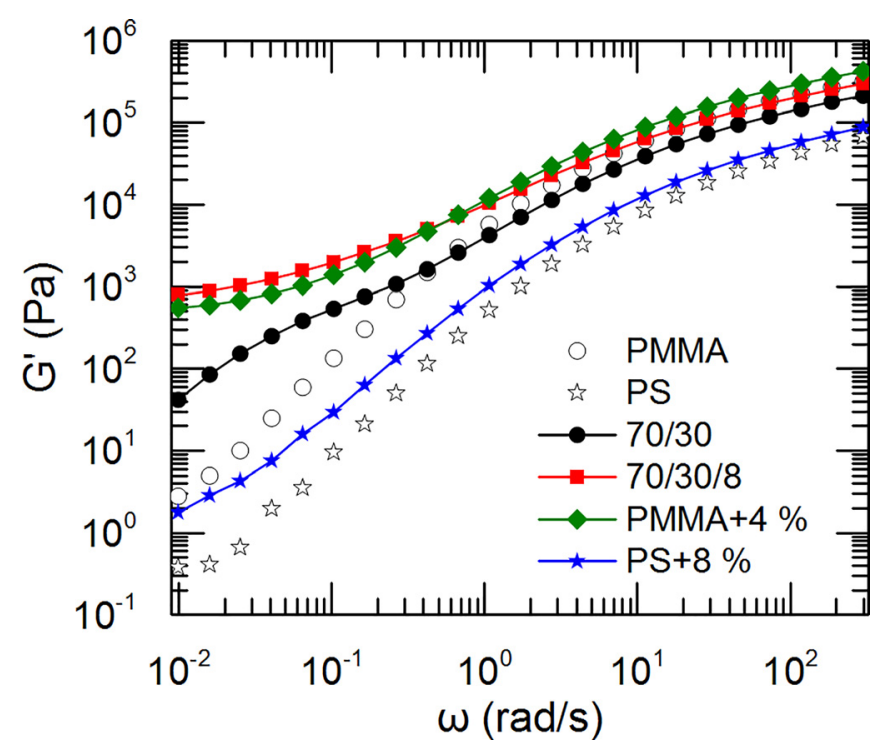

FIG. 8. Storage moduli of PMMA $+4 \%$, PS $+8 \%, 70 / 30 / 0$ and $70 / 30 /$ 8 blends as a comparison.

$$
\% C_{s a t}=\frac{3 e}{R_{v}} \% P S,
$$

where $e$ is the thickness of one clay platelet, $R_{v}$ is the PS average droplet radius, and \%PS is the volume fraction of PS.

The authors primarily estimate that the clay is exfoliated, and thus use the thickness of a single clay platelet in their equations. In this study, since the clay may not be fully exfoliated, we considered that the clay could be held in tactoids containing 1, 2, 3, or 4 layers of clay. The results are reported in Table VI, while the thickness is calculated, adding successive layers of clay ( $1 \mathrm{~nm}$ thickness) and the basal spacing reported in Table III. The percentage of clay needed to saturate the interface is smaller for $70 / 30$ blends, which is normal because as the droplets are bigger, the total interfacial area is smaller than for $90 / 10$ blends. If the clay saturates the interface for concentrations below $4 \%$, then the sheets

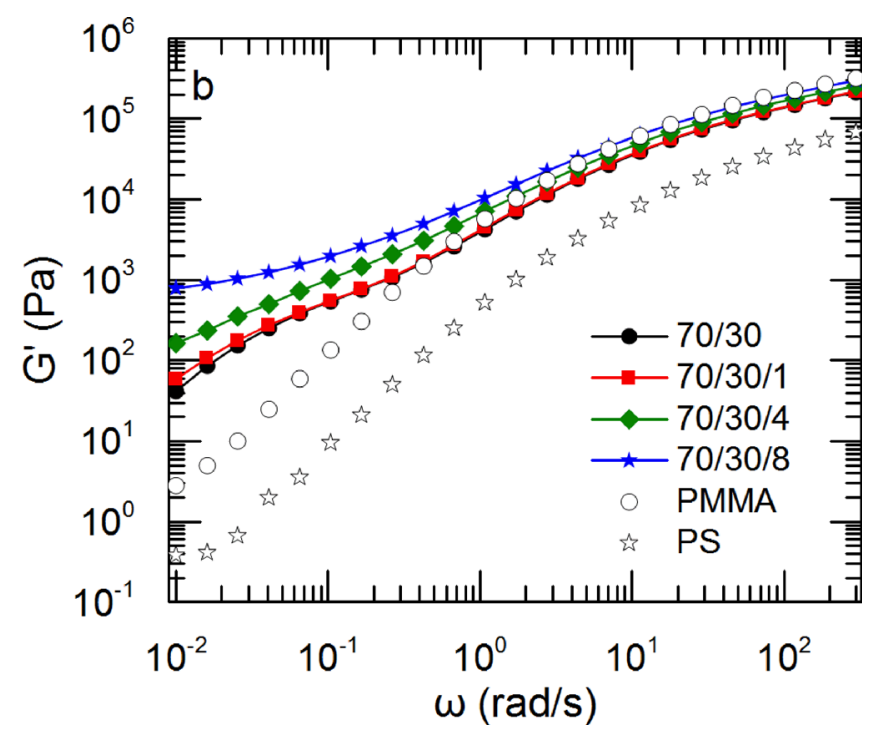

FIG. 7. Storage moduli of PMMA/PS/Cloisite20A blends for 90/10 (a) and 70/30 (b) concentrations and different levels of clay at $200{ }^{\circ} \mathrm{C}$. 

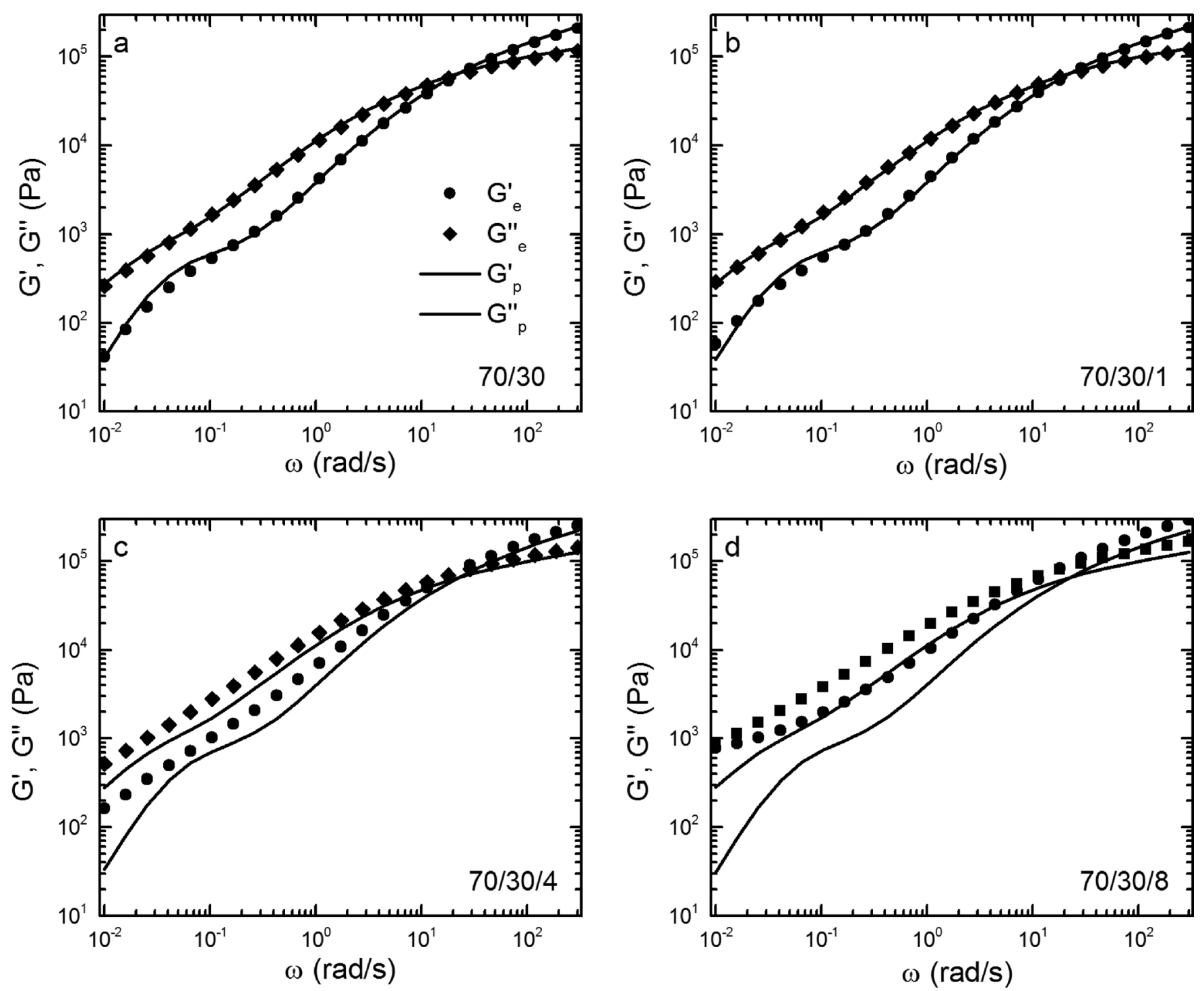

FIG. 9. Experimental storage moduli $\left(G^{\prime}{ }_{e}\right)$ and loss moduli $\left(G^{\prime \prime}{ }_{e}\right)$ and their prediction by the Palierne model $\left(G_{p}^{\prime}\right.$ and $\left.G^{\prime \prime}{ }_{p}\right)$ of (a) $70 / 30,(b) 70 / 30 / 1$, (c) $70 / 30 /$ 4 , and (d) $70 / 30 / 8$ blends at $200^{\circ} \mathrm{C}$.

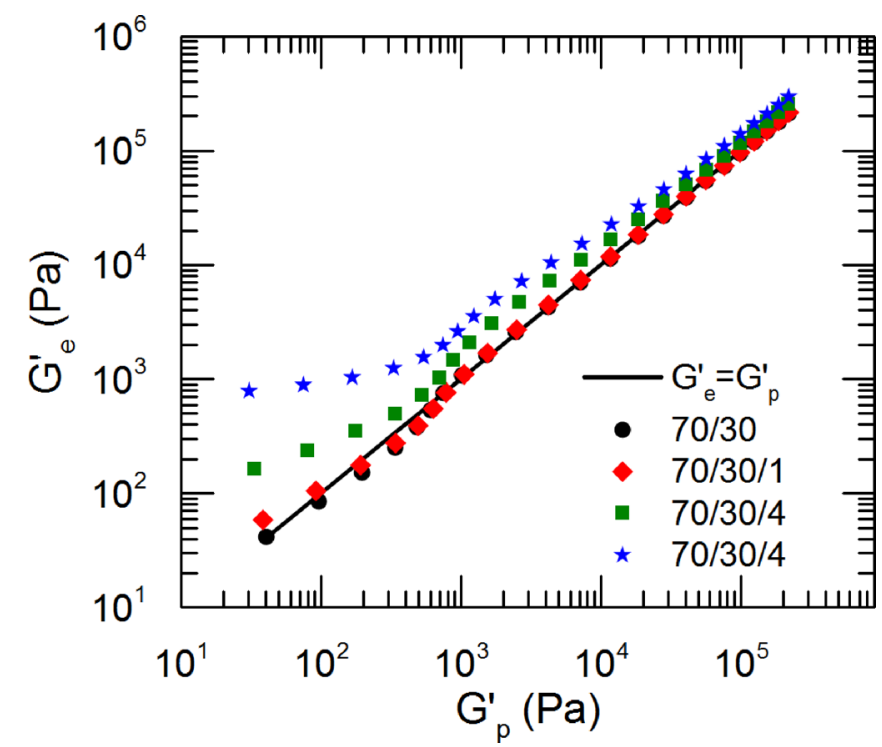

FIG. 10. Experimental storage moduli $\left(G_{e}^{\prime}\right)$ as a function of theoretical storage moduli $\left(G_{p}^{\prime}\right)$. are stacked together into 1-2 sheets tactoids on average (see also Fig. 11).

Concerning the 90/10 blends, nothing could be inferred, as no noticeable difference could be seen directly on neat rheological results. In that case, Table VI indicates that the interface was not saturated in those blends, and TEM pictures discussed previously showed that clay is located at the interface (Fig. 5).

This presence of clay at the interface limits the possible hypotheses for the compatibilization mechanism to the

TABLE VI. Weight percentage of clay with respect to PS needed to saturate the interface.

\begin{tabular}{lccc}
\hline \hline Number of sheets & Thickness (nm) & \% C 70/30 & $\%$ C 90/10 \\
\hline 1 & 1.0 & 0.8 & 4.0 \\
2 & 5.6 & 4.5 & 22.5 \\
3 & 10.2 & 8.3 & 40.9 \\
4 & 14.8 & 12.0 & 59.4 \\
\hline \hline
\end{tabular}




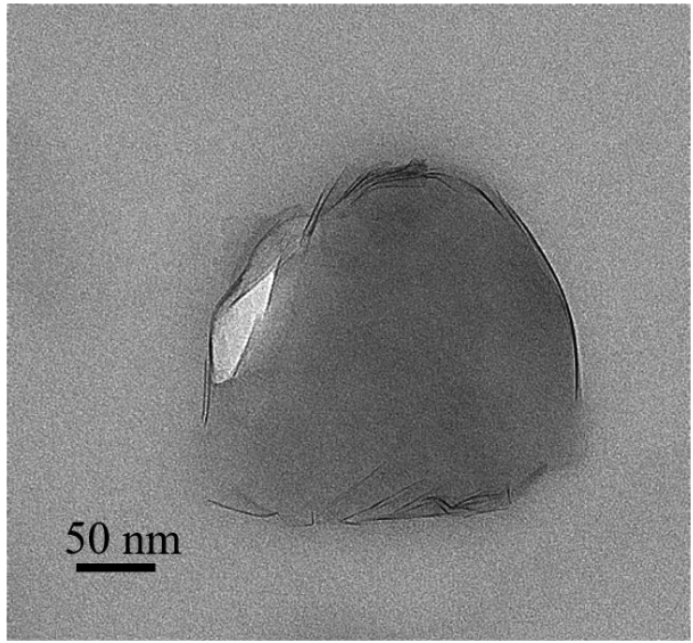

FIG. 11. Typical TEM of a PMMA/PS/Cloisite 20A droplet.
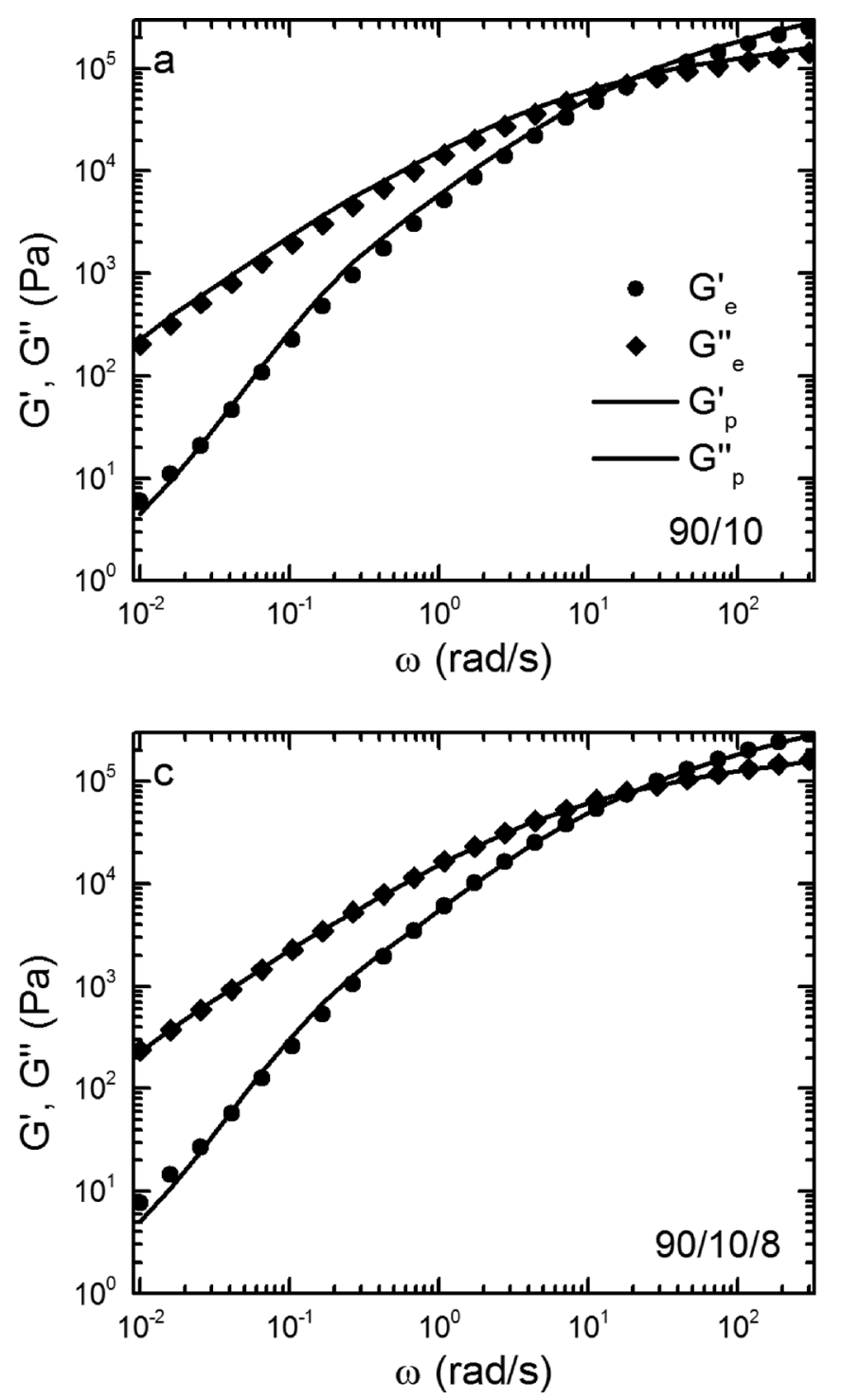

decrease in interfacial tension and/or the inhibition of coalescence by steric hindrance, solid barrier, or Marangoni stress.

\section{Interfacial tension}

The interfacial tension was calculated by fitting the simplified Palierne model on SAOS experimental data. Figure 12 shows the fits of the Palierne model on 90/10 blends.

The values reported in Table VII show that the interfacial tension decreases upon addition of clay. Our results corroborate those of Yee et al. [24], who found similar values of interfacial tension fitting Bousmina's model (see Table VII). The interfacial tension is lower for the 70/30 blend than for the $90 / 10$ blend. This has already been shown by Calvão et al. [33] who found similar values $(0.9 \mathrm{mN} / \mathrm{m})$ for a $70 / 30$ PMMA/PS blend.

In the case of a block copolymer, a decrease in interfacial tension is often combined with Marangoni stresses to explain the compatibilization mechanism. As we showed that an

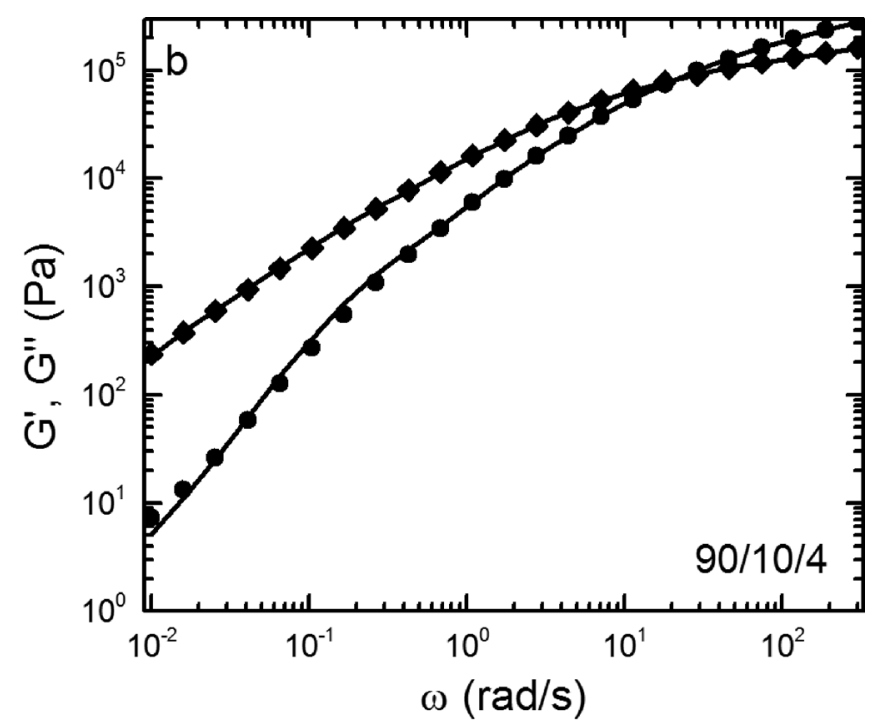

FIG. 12. Experimental storage moduli (circles) and loss moduli (diamonds) and their fit of the Palierne model (lines) on the (a) 90/10, (b) 90/10/4, and (c) 90/ $10 / 8$ blends at $200^{\circ} \mathrm{C}$. 
TABLE VII. Values of interfacial tension $\left(\alpha^{P}\right)$ found by fitting the simplified Palierne model on SAOS experimental results and $\left(\alpha^{Y}\right)$ values found by Yee et al. (Ref. 24).

\begin{tabular}{|c|c|c|c|c|}
\hline Composition & $\begin{array}{l}\% \text { Compatibilizer } \\
\text { with respect to PS }\end{array}$ & $\begin{array}{l}\% \text { Compatibilizer } \\
\text { with respect to the } \\
\text { whole blend }\end{array}$ & $\begin{array}{c}\alpha^{P} \\
(\mathrm{mN} / \mathrm{m})\end{array}$ & $\begin{array}{c}\alpha^{Y} \\
(\mathrm{mN} / \mathrm{m})\end{array}$ \\
\hline \multirow[t]{4}{*}{$90 / 10$} & 0 & 0 & $1.35 \pm 0.16$ & 1.4 \\
\hline & 1 & 0.1 & - & - \\
\hline & 4 & 0.4 & $0.70 \pm 0.04$ & 0.97 \\
\hline & 8 & 0.8 & $0.65 \pm 0.08$ & 0.85 \\
\hline $70 / 30$ & 0 & 0 & $0.89 \pm 0.12$ & - \\
\hline
\end{tabular}

interfacial tension decrease occurs upon the addition of clay, the relaxation phenomena were investigated.

\section{E. Relaxation phenomena}

The relaxation phenomena were studied by using the relaxation spectra inferred from the SAOS measurements. The non-linear regularization technique was used to convert the dynamic results into continuous relaxation spectra [27]. Figure 13 shows the corresponding weighted relaxation modulus $\left(H(\tau)^{*} \tau\right)$ as a function of the time $\tau$ of PMMA, PS, and pure blends. Two peaks can be identified for the blends: One related to the relaxation times of the blends phases (PS and PMMA) which are overlayed because they are very close to one another [24], and a second, which is associated with the form relaxation of the dispersed droplets. When the concentration of the dispersed phase is higher, the peaks have more amplitude, and the second peak, corresponding to the relaxation of the droplets, is longer because for $30 \%$ of PS, the droplets are larger.

For both 90/10 blends and 70/30 blends (see Fig. 14), the rise of the relaxation modulus at long times with the addition of clay could suggest the presence of an additional relaxation phenomenon at longer times. One way to obtain data at those times is to use creep experiments as a complimentary technique [28]. In this case, another approach was

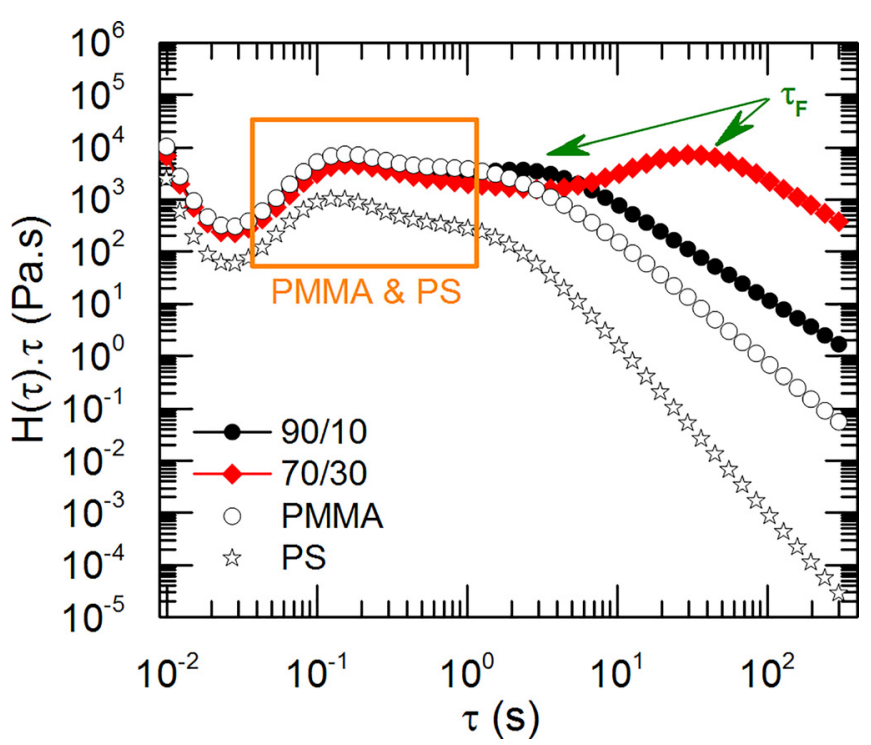

FIG. 13. Weighted relaxation spectra of pure blends and materials.

used consisting of increasing the temperature as it decreases relaxation times. Therefore, additional measurements were carried out at $220^{\circ} \mathrm{C}$. Figure 15 (a) shows the results. As expected, the pure materials with clay exhibit only the relaxation of PMMA or PS chains. The increase at long times for PS $+8 \%$ is believed to be due to the relaxation of clay network or agglomerates. Concerning the $90 / 10$ blends, a third relaxation time is revealed. This relaxation time is believed to be due to the Marangoni stress, as neither PMMA $+1 \%$ nor PS $+8 \%$ have a similar peak as the $90 / 10 / 8$ blend [see Fig. 15(b)], and clay is located at the interface. This is the first time that this relaxation time has been observed in the case of nanoparticles. The Marangoni stress time decreases with increasing concentration of clay so even if the relaxation does not appear for 90/10/1 the increase at long time indicates a possible relaxation longer than $300 \mathrm{~s}$. This trend is in accordance with the results obtained by several researchers in the case of block copolymer compatibilizers
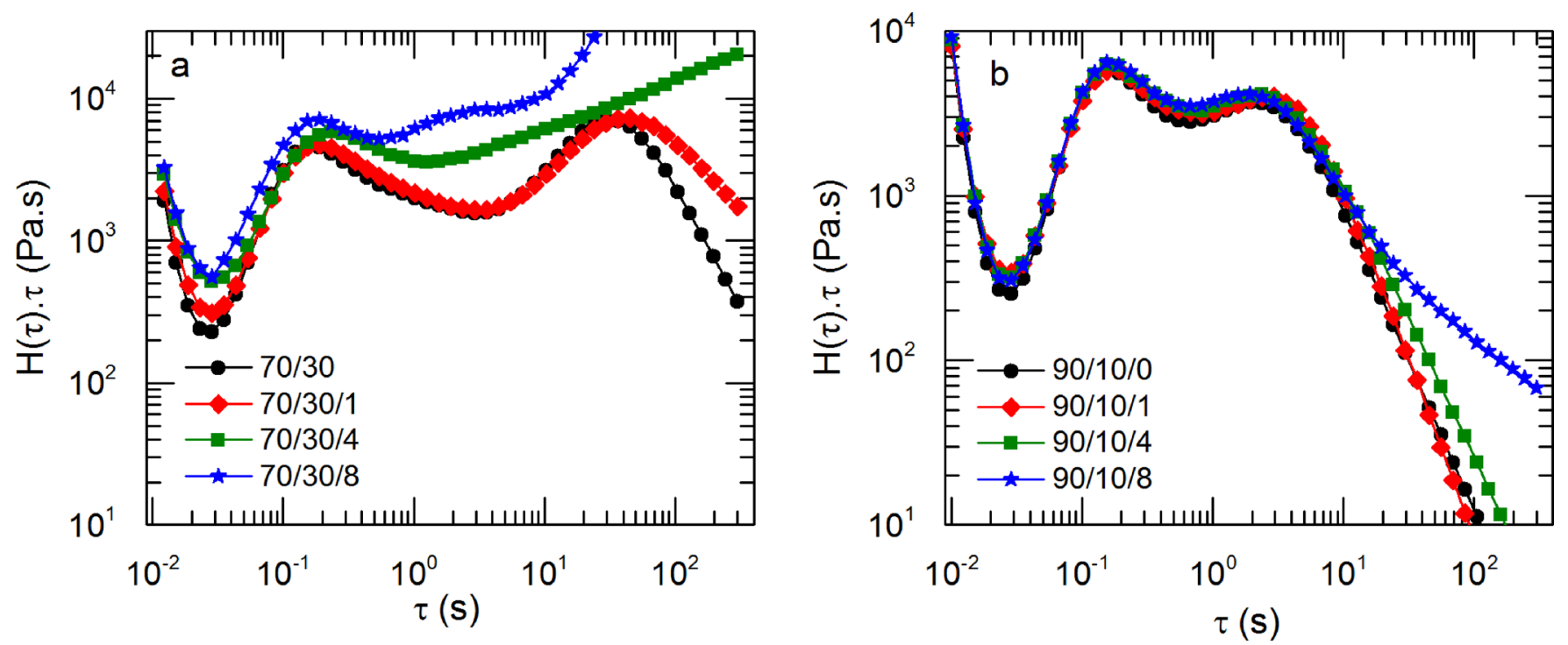

FIG. 14. Weighted relaxation spectra of (a) $70 / 30$ and (b) $90 / 10$ blends with different levels of Cloisite $20 \mathrm{~A}$ at $200^{\circ} \mathrm{C}$. 

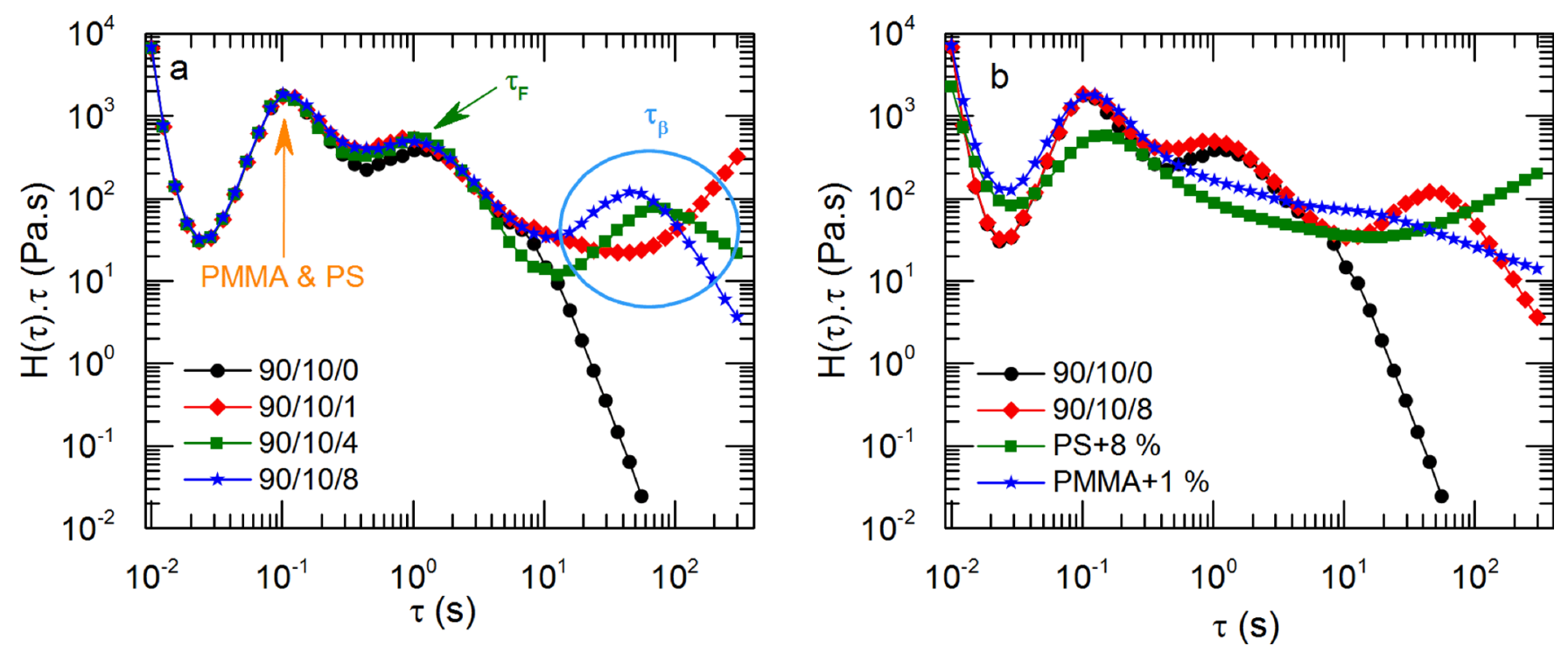

FIG. 15. Relaxation spectrum of PMMA + (PS + C) (90/10) (a) blends with different levels of Cloisite $20 \mathrm{~A}$ at $220^{\circ} \mathrm{C}$, (b) comparison of $90 / 10 / 8$ blends with PMMA $+1 \%$ and PS $+8 \%$.

[9,23,31,36-38]. This means that Cloisite 20A behaves similarly to block copolymers.

The Palierne model described by Jacobs et al. takes into account a second relaxation phenomenon that has been shown to correspond to the Marangoni stress in previous studies [9,24,31]. In order to compare the values found experimentally using the relaxation spectra to the values predicted by the Palierne model, an estimation of the shear modulus of the interface is needed. Indeed, the shear modulus of the interface is likely to be influenced by the nature of the compatibilizer so block copolymers may correspond to a different interfacial shear modulus than nanoparticles. The literature provides values for block copolymers [9,24,31] as compatibilizer, but not for clay nanoparticles. By applying Eqs. (5) and (6), corresponding to the version of the Palierne model given by Jacobs et al. [31], the results at $200^{\circ} \mathrm{C}$ allow an estimation of the shear moduli of the interface $\beta_{20}$. The results show that $\beta_{20}$ is higher than for the block copolymer (see Table VIII). However, the tendency is the same: $\beta_{20}$ increases with the addition of clay as well as with addition of block copolymers. These results are in accordance with the observations of Labaume et al. [39].

At $220^{\circ} \mathrm{C}$, a theoretical estimation of the relaxation times was carried out, considering the influence of temperature on the interfacial tension and the interfacial shear modulus to be negligible over $20^{\circ} \mathrm{C}$ (i.e., from 200 to $220^{\circ} \mathrm{C}$ ). The interfacial tension was extracted from Table VII, $R_{v}$ was extracted from Table II, and $\beta_{20}$ was the one calculated previously (reported in Table VIII). The results show good agreement between the theoretical and experimental scenarios for droplet shape relaxation times, even though the model underestimates the results. Regarding the Marangoni stress relaxation, the values were much smaller than those given by experiments. According to the theoretical results, the Marangoni stress relaxation should be around $1.5 \mathrm{~s}$, which would likely be overlayed with the droplet shape relaxation at $0.5 \mathrm{~s}$. This underestimation was also observed in the publication of Yee et al. [24]; however, it is significantly more dramatic in this case than in their case, which may be due to the fact that nanoparticles are used instead of copolymers, which would change the interface properties.

In the case of $70 / 30$ blends, the relaxation spectra at $220^{\circ} \mathrm{C}$ are not displayed as no third relaxation time was observed. In the case of a saturated interface (70/30/4 and 70/30/8), no Marangoni stress may even be present, as the clay may not be able to move around the droplets enough. Here, the compatibilization could be due to a physical barrier created by clay around the droplets and/or an increase in

TABLE VIII. Experimental values of the relaxation times $\tau_{F}{ }^{E}$ and $\tau_{\beta}{ }^{E}$ extracted from the relaxation spectra; the theoretical values $\tau_{F}^{T}$ and $\tau_{\beta}{ }^{T}$ were found using Eqs. (5) and (6) and $\beta_{20}$ the shear moduli of the interface.

\begin{tabular}{|c|c|c|c|c|c|c|c|c|c|}
\hline & \multirow[b]{2}{*}{$\%$ Cloisite 20A } & $\tau_{F}^{E}(\mathrm{~s})$ & $\tau_{\beta}^{E}(\mathrm{~s})$ & \multirow[b]{2}{*}{$\beta_{20}{ }^{\mathrm{a}}(\mathrm{mN} / \mathrm{m})$} & \multirow[b]{2}{*}{$\beta_{20}^{\mathrm{b}}(\mathrm{mN} / \mathrm{m})$} & $\tau_{F}^{E}(\mathrm{~s})$ & $\tau_{\beta}^{E}(\mathrm{~s})$ & $\tau_{F}^{T}(\mathrm{~s})$ & $\tau_{\beta}^{T}(\mathrm{~s})$ \\
\hline & & & & & & \multicolumn{4}{|c|}{$220^{\circ} \mathrm{C}$} \\
\hline \multirow[t]{4}{*}{$90 / 10$} & 0 & 2.95 & - & - & - & 0.82 & - & 0.73 & - \\
\hline & 1 & 2.60 & $\mathrm{c}$ & 0.80 & 0.18 & 0.70 & a & 0.55 & 1.51 \\
\hline & 4 & 2.15 & c & 1.15 & 0.22 & 0.50 & 74 & 0.46 & 1.58 \\
\hline & 8 & 1.71 & c & 1.32 & 0.30 & 0.50 & 50 & 0.37 & 1.45 \\
\hline
\end{tabular}

${ }^{\mathrm{a} C a l c u l a t e d}$ using Eqs. (5) and (6).

${ }^{\mathrm{b}}$ Extracted from Ref. 31.

${ }^{\mathrm{c}}$ Not observed. 
matrix viscosity due to the presence of clay. Knowing that $8 \%$ of clay with respect to PS corresponds to $1.7 \%$ with respect to PMMA, and by recalling the results found on PMMA + clay complex viscosity (Table V and Fig. 4), we know that PMMA $+2 \%$ does not induce any noticeable increase in viscosity. Moreover, as clay is also present at the interface, the clay content in PMMA is strictly lower than $1.7 \%$. We can conclude that the presence of clay in PMMA for $70 / 30 / 8$ blends does not influence the viscosity of the matrix. As such, for 70/30/4 and 70/30/8 blends, the compatibilization mechanism is believed to be due to a decrease in interfacial tension and physical barrier, what is also called the Pickering effect, around the droplets.

\section{CONCLUSION}

The aim of this work was to understand the compatibilization mechanism of PMMA/PS/Cloisite $20 \mathrm{~A}$ blends. First, the morphology was assessed, a decrease in the droplet radius upon addition of clay indicated a compatibilizing effect. The dispersion and localization of clay was then studied as it is a key element in understanding compatibilization mechanisms. The results on pure materials showed that clay was better dispersed in PMMA than in PS. In the blends, it was shown that clay localizes itself to the interface until saturation of the interfacial area, after which the remaining clay disperses in PMMA rather than in PS. By considering the blends with a saturated interface, it was possible to say that clay is dispersed in 1-2 sheets on average. Linear rheology results combined with the Palierne model showed the compatibilization mechanism to be due to a decrease in interfacial tension as well as Marangoni stresses in the case of an unsaturated interface. This is the first time that Marangoni stresses are shown in the case of nanoparticles. In other words, these results showed that Cloisite 20A behaves similarly to block copolymers. Although small differences can be observed due to the inherent nature of the ceramic particles: (1) The interfacial shear modulus $\left(\beta_{20}\right)$ from the Palierne model is higher than the ones observed for block copolymers, (2) the Marangoni stress time is longer in the case of nanoparticles as an increase in the temperature of the SAOS experiments was needed to be able to observe it. This indicates that the mobility of ceramic particles around the droplet is smaller than the one of block copolymers which have affinity with both phases.

\section{ACKNOWLEDGMENTS}

Financial supports from the Natural Sciences and Engineering Research Council of Canada (NSERC), Fundação de Amparo à Pesquisa do Estado de São Paulo (FAPESP), Conselho Nacional de Pesquisa e Desenvolvimento (CNPq), Coordenação de Aperfeiçoamento de Pessoal de Nível Superior (CAPES), and Ecole de technologie supérieure (ETS) are gratefully acknowledged. The authors are thankful to the Facility for Electron Microscopy Research (FEMR) department of McGill University for some of the TEM pictures.

\section{References}

[1] Van Puyvelde, P., and P. Moldenaers, "Rheology and morphology development in immiscible polymer blends," Rheol. Rev. 101-145 (2005).

[2] Tucker, C. L., and P. Moldenaers, "Microstructural evolution in polymer blends," Annu. Rev. Fluid Mech. 34, 177-210 (2002).

[3] DeLeo, C. L., and S. S. Velankar, "Morphology and rheology of compatibilized polymer blends: Diblock compatibilizers vs crosslinked reactive compatibilizers," J. Rheol. 52, 1385-1404 (2008).

[4] Souza, A. M. C., and N. R. Demarquette, "Influence of coalescence and interfacial tension on the morphology of PP / HDPE compatibilized blends," Polymer 43(14), 3959-3967 (2002).

[5] Sundararaj, U., and C. W. Macosko, "Drop breakup and coalescence in polymer blends: The effects of concentration and compatibilization," Macromolecules 28(8), 2647-2657 (1995).

[6] Macaubas, P. H. P., and N. R. Demarquette, "Morphologies and interfacial tensions of immiscible polypropylene/polystyrene blends modified with triblock copolymers," Polymer 42(6), 2543-2554 (2001).

[7] de Souza, A. M. C., P. S. Calvão, and N. R. Demarquette, "Linear viscoelastic behavior of compatibilized PMMA/PP blends," J. Appl. Polym. Sci. 129(3), 1280-1289 (2013).

[8] Yee, M., A. M. C. Souza, T. S. Valera, and N. R. Demarquette, "Stress relaxation behavior of PMMA/PS polymer blends," Rheol. Acta 48(5), 527-541 (2009).

[9] Riemann, R., H. Cantow, and C. Friedrich, "Interpretation of a new interface-governed relaxation process in compatibilized polymer blends," Macromolecules 30(18), 5476-5484 (1997).

[10] Elias, L., F. Fenouillot, J. C. Majesté, P. Alcouffe, and P. Cassagnau, "Immiscible polymer blends stabilized with nano-silica particles: Rheology and effective interfacial tension," Polymer 49(20), 4378-4385 (2008).

[11] Vermant, J., G. Cioccolo, K. Golapan Nair, and P. Moldenaers, "Coalescence suppression in model immiscible polymer blends by nano-sized colloidal particles," Rheol. Acta 43(5), 529-538 (2004).

[12] Taguet, A., P. Cassagnau, and J.-M. Lopez-Cuesta, "Structuration, selective dispersion and compatibilizing effect of (nano)fillers in polymer blends," Prog. Polym. Sci. 39(8), 1526-1563 (2014).

[13] Fenouillot, F., P. Cassagnau, and J.-C. Majesté, "Uneven distribution of nanoparticles in immiscible fluids: Morphology development in polymer blends," Polymer 50(6), 1333-1350 (2009).

[14] Monfared, A., and A. Jalali-Arani, "Morphology and rheology of (styrene-butadiene rubber/acrylonitrile-butadiene rubber) blends filled with organoclay: The effect of nanoparticle localization," Appl. Clay Sci. 108, 1-11 (2015).

[15] Parpaite, T., B. Otazaghine, A. S. Caro, A. Taguet, R. Sonnier, and J. M. Lopez-Cuesta, "Janus hybrid silica/polymer nanoparticles as effective compatibilizing agents for polystyrene/polyamide-6 melted blends," Polymer 90, 34-44 (2016).

[16] Parpaite, T., B. Otazaghine, A. Taguet, R. Sonnier, A. S. Caro, and J. M. Lopez-Cuesta, "Incorporation of modified Stöber silica nanoparticles in polystyrene/polyamide- 6 blends: Coalescence inhibition and modification of the thermal degradation via controlled dispersion at the interface," Polymer 55(11), 2704-2715 (2014).

[17] Huang, M., and H. Guo, "The intriguing ordering and compatibilizing performance of Janus nanoparticles with various shapes and different dividing surface designs in immiscible polymer blends," Soft Matter 9(30), 7356-7368 (2013).

[18] Delbem, M. F., T. S. Valera, F. R. Valenzuela-Diaz, and N. R. Demarquette, "Modification of a Brazilian smectite clay with different quaternary ammonium salts," Quim. Nova 33(2), 309-315 (2010). 
[19] Cavallaro, G., G. Lazzara, S. Milioto, F. Parisi, and V. Sanzillo, "Modified halloysite nanotubes: Nanoarchitectures for enhancing the capture of oils from vapor and liquid phases," ACS Appl. Mater. Interfaces 6(1), 606-612 (2014).

[20] Jinhua, W., Z. Xiang, Z. Bing, Z. Yafei, Z. Rui, L. Jindun, and C. Rongfeng, "Rapid adsorption of Cr (VI) on modified halloysite nanotubes," Desalination 259(1-3), 22-28 (2010).

[21] Sinha Ray, S., S. Pouliot, M. Bousmina, and L. A. Utracki, "Role of organically modified layered silicate as an active interfacial modifier in immiscible polystyrene/polypropylene blends," Polymer 45(25), 8403-8413 (2004).

[22] Graebling, D., R. Muller, and J. F. Palierne, "Linear viscoelastic behavior of some incompatible polymer blends in the melt. Interpretation of data with a model of emulsion of viscoelastic liquids," Macromolecules 26(2), 320-329 (1993).

[23] Van Hemelrijck, E., P. Van Puyvelde, S. Velankar, C. W. Macosko, and P. Moldenaers, "Interfacial elasticity and coalescence suppression in compatibilized polymer blends," J. Rheol. 48(1), 143-158 (2003).

[24] Yee, M., P. S. Calvão, and N. R. Demarquette, "Rheological behavior of poly(methyl methacrylate)/polystyrene (PMMA/PS) blends with the addition of PMMA-ran-PS," Rheol. Acta 46(5), 653-664 (2007).

[25] Wu, D., Y. Zhang, L. Yuan, M. Zhang, and W. Zhou, "Viscoelastic interfacial properties of compatibilized poly( $\varepsilon$-caprolactone)/polylactide blend," J. Polym. Sci. Part B Polym. Phys. 48(7), 756-765 (2010).

[26] Jeon, H. K., and C. W. Macosko, "Visualization of block copolymer distribution on a sheared drop," Polymer 44(18), 5381-5386 (2003).

[27] Honerkamp, J., and J. Weese, "A nonlinear regularization method for the calculation of relaxation spectra," Rheol. Acta 32(1), 65-73 (1993).

[28] Shaayegan, V., P. Wood-Adams, and N. R. Demarquette, "Linear viscoelasticity of immiscible blends: The application of creep," J. Rheol. 56(5), 1039-1056 (2012).

[29] Palierne, J. F., "Linear rheology of viscoelastic emulsions with interfacial tension," Rheol. Acta 29(3), 204-214 (1990).
[30] Bousmina, M., P. Bataille, S. Sapieha, and H. P. Schreiber, "Comparing the effect of corona treatment and block copolymer addition on rheological properties of polystyrene/polyethylene blends," J. Rheol. 39(3), 499-517 (1995).

[31] Jacobs, U., M. Fahrlander, J. Winterhalter, and C. Friedrich, "Analysis of Palierne's emulsion model in the case of viscoelastic interfacial properties," J. Rheol. 43(6), 1495-1509 (1999).

[32] Saltikov, S. A., "The determination of the size distribution of particles in an opaque material from a measurement of the size distribution of their sections," in Stereology, edited by H. Elias (Springer, Berlin, Heidelberg, 1967), pp. 163-173.

[33] Calvão, P. S., M. Yee, and N. R. Demarquette, "Effect of composition on the linear viscoelastic behavior and morphology of PMMA/PS and PMMA/PP blends," Polymer 46(8), 2610-2620 (2005).

[34] Amurin, L. G., D. J. Carastan, and N. R. Demarquette, "Morphological evolution of block copolymer nanocomposites submitted to extensional flows," J. Rheol. 60(1), 175-189 (2016).

[35] Vergnes, B., "The use of apparent yield stress to characterize exfoliation in polymer nanocomposites," Int. Polym. Process. 26(2), 229-232 (2011).

[36] Lertwimolnun, W., and B. Vergnes, "Effect of processing conditions on the formation of polypropylene/organoclay nanocomposites in a twin screw extruder," Polym. Eng. Sci. 46(3), 314-323 (2006).

[37] Van Hemelrijck, E., P. Van Puyvelde, C. W. Macosko, and P. Moldenaers, "The effect of block copolymer architecture on the coalescence and interfacial elasticity in compatibilized polymer blends," J. Rheol. 49(3), 783-798 (2005).

[38] Friedrich, C., and Y. Y. Antonov, "Interfacial relaxation in polymer blends and Gibbs elasticity," Macromolecules 40(4), 1283-1289 (2007).

[39] Labaume, I., P. Médéric, J. Huitric, and T. Aubry, "Comparative study of interphase viscoelastic properties in polyethylene/polyamide blends compatibilized with clay nanoparticles or with a graft copolymer," J. Rheol. 57(2), 377-392 (2013). 